\title{
Finite element analysis of the creep crack growth of T-type brazed joints Dongxing Wang ${ }^{a}$, Guoyan Zhou ${ }^{\text {b }}$, Baoan Wang, Yucai Zhang \\ East China University of Science and Technology, Shanghai 200237, China \\ a1955731608@qq.com, bzhougy@ecust.edu.cn
}

Keywords: T-type brazed joints; creep; crack growth; finite element method

\begin{abstract}
Plate-fin heat exchangers are widely used in the field of nuclear waste heat recovery due to their high heat transfer efficiency and compact structures. The vacuum brazing technology is frequently employed to package these structures. Under high temperature, high pressure and harsh working conditions, cracks caused by creep or creep damage can initiate and growth easily in the brazed joints. they will further bring about the failure of structures. In this work, the creep failure behavior of T-type brazed joints at $650^{\circ} \mathrm{C}$ was investigated by finite element method. The creep crack initiation and growth of T-brazed joints were analyzed. Combined with actual vacuum brazing process, the effect of brazing metal thickness on the creep crack initiation and growth of the brazed joint were analyzed. Results showed that the edge of the brazing material was most vulnerable to damage. Later on, the central area of the brazing metal was subsequently damaged.An appropriate increase of the brazing metal thickness is thought to be helpful to prolong the creep life of the T-type brazed joints.
\end{abstract}

\section{Introduction}

Plate-fin heat exchangers are often used in the field of nuclear power for waste heat recovery. However, they are not continuous in structure, nor do their mechanical properties match, plate-fin heat exchanger joints are therefore prone to creep cracks and cavities. When a crack reaches its critical size, it often leads to catastrophic consequences[1]. Therefore, it is imperative to study the characteristics of the creep crack growth of brazed joints at elevated temperatures. With the development of computer technology, using finite element method to study the mechanical behavior of brazed joints has gradually drawn the attention of researchers. HAN Fei et al. [2] carried out the simulation to study the residual stress of ceramic metal brazing joints. Tu Shandong et al. [3] used FEM to analyze the creep damage of 304 stainless steel brazed joints in the plate-fin heat exchanger, whose results showed that the brazing area was a weak region in the brazing joint. Chen Jianjun et al. [4] analysed the creep damage of a 304 / BNi2 lap joint, The results also showed that the brazing area was the weakest region of the joint. Jiang Wenchun et al. [5] considered the steady state creep of a brazing filler metal, the effect of brazing metal thickness on the creep of stainless steel plate fin structure was analyzed by using Norton constitutive. However, the aforemensioned studies did not take into account the primary stage of the creep of the brazing filler metal during creep simulations[2-5]. At the primary stage strain of the brazing material account for about $10 \%$ of the total creep strain, and the neglect of the primary stage may lead to large error of simulation results. Therefore, it is the key to accurately study the high temperature mechanical properties of brazed joints to consider the primary-stage creep of brazing metals.

Based on a modified stress-based damage model, with the incorporation of the primary stage of the creep of the brazing metal, the creep crack growth in the T-type brazed joint wasconsequently simulated. Both the behavior of the creep crack growth and the effect of the thickness of the brazed joint on the creep performance of the T-brazing joint were studied in detail. This work can be a basis for evaluating the creep life of the brazed joints.

\section{FE model}

Creep damage constitutive model.

In this paper, a modifiey L-M model obtained by combining the K-R creep damage model[6]was 
employed. The model can be expressed as follows:

$$
\begin{gathered}
\dot{\varepsilon}_{i j}^{c}=\frac{3}{2} B_{0} \sigma_{e q}^{n_{0}-1} S_{i j} t^{m-1}+\frac{3}{2} B \sigma_{e q}^{n-1} S_{i j} \exp \left[\frac{2(n+1)}{\pi \sqrt{1+(3 / n)}} \omega^{3 / 2}\right] \\
\dot{\omega}=\frac{A\left[1-\exp \left(-q_{2}\right)\right]}{q_{2}} \sigma_{r}^{p} \exp \left(q_{2} \omega\right) \\
\sigma_{r}=\alpha \cdot \sigma_{I}+\alpha \cdot \sigma_{e q}
\end{gathered}
$$

Where $B_{0}, n_{0}, m$ are material constants of the primary creep stage of the solder, $\dot{\varepsilon}_{i j}^{c}$ is the creep strain rate tensor, $A 、 B 、 n 、 q_{2} 、 p$ are material constants, $\sigma_{e q}$ and $\sigma_{I}$ are the von Mises stress and Maximum principal stress,respectively. $\boldsymbol{S}_{i j}$ is the deviatoric stress, $\omega$ is the damage state variable, $\sigma_{r}$ is the equivalent stress, $\alpha$ is the multi-axial stress state parameter. From the formula (1), we can see that the model combines the advantages of the K-R model, taking into account the first stage of the creep of the solder.

\section{Model parameters and material parameters.}

The model parameters for $316 \mathrm{~L}$ at $650^{\circ} \mathrm{C}$ are $B=1.133 \mathrm{e}-20, n=8.3076, A=1.216 \mathrm{E}-22$, and $P=$ 8.5911[7-8]. $q_{2}$ in the L-M model is hard to obtain. According to the empirical formula, $q_{2}=\phi+2$, where $\phi$ is a constant in the K-R model[9]. $\phi$ can be obtained by fitting the normalized uniaxial creep strain curve , by doing so, $\phi$ was identified,namely $\phi=6.075[10]$, then $q_{2}=8.075$. The creep parameters of the Nickel-based brazing metal $\mathrm{BNi}-2$ at $650^{\circ} \mathrm{C}$ are as follows[7]. Therefore, the material parameters of $316 \mathrm{~L}$ and $\mathrm{BNi} 2$ at $650^{\circ} \mathrm{C}$ are shown in Table 1.The elastic modulus of 316L and $\mathrm{BNi}-2$ at $650^{\circ} \mathrm{C}$ is $149 \mathrm{GPa}$ and $170 \mathrm{GPa}$, respectively; the yield strength $161 \mathrm{MPa}$ and $200 \mathrm{MPa}$ respectively[11-12].

Tab.1 Creep parameters of $\mathrm{BNi} 2$ and $316 \mathrm{~L}$ at $650^{\circ} \mathrm{C}$

\begin{tabular}{|c|c|c|c|c|c|c|c|c|c|}
\hline parameters & $B_{0}$ & $n_{0}$ & $m$ & $A$ & $B$ & $n$ & $p$ & $q$ & $\alpha[13]$ \\
\hline BNi2 & $\begin{array}{c}1.562 \mathrm{e}- \\
7\end{array}$ & 1.965 & 0.29 & $7.899 \mathrm{e}-9$ & $8.016 \mathrm{e}-11$ & 2.92 & 2.70 & 3.2307 & 0.15 \\
\hline 316L & - & - & - & $\begin{array}{c}1.216 \mathrm{e}-2 \\
2\end{array}$ & $1.133 \mathrm{e}-20$ & 8.3076 & 8.591 & 8.075 & 0.43 \\
\hline
\end{tabular}

\section{FE model and boundary conditions.}

In terms of the actual plate fin structure in Fig. 1a, the finite element model shown in Fig. 1b was established, where the thickness of the brazing seam was $80 \mu \mathrm{m}$. The bottom end of the T-brazing joint specimen was defined as encastre, i.e $\mathrm{U} 1=\mathrm{U} 2=\mathrm{UR} 3=0$, the freedoms of the $\mathrm{X}$ direction displacement and rotation were restricted at the top end, i.e $\mathrm{U} 1=\mathrm{UR} 3=0$, the $15 \mathrm{MPa}$ load was exerted on the top end of the T-brazed joint in the Y direction. The stress state of the brazed joint was closer to the plane strain state than plane strain state when a brazed joint failed, so in the finite element analysis, the plane strain unit CPE4R was chosen for the brazing filler metal. Considered that the brazing filler metal area was invariably the weakest region of a brazing joint, smaller element size was used when the brazing filler metal area was meshed, as shown in Fig2, where the red area indicated the brazing area.

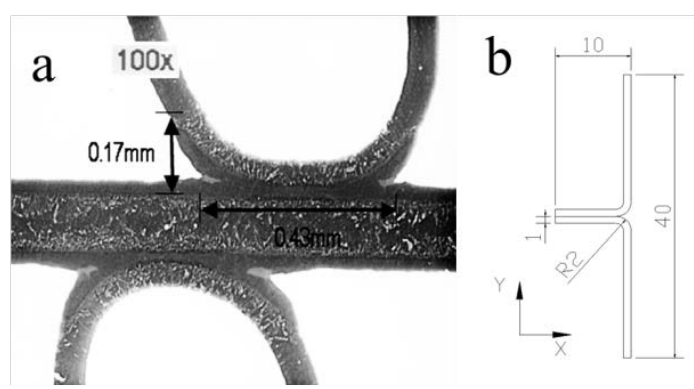

Fig.1(a)Plate-fin structure (b)Geometrical dimensions of T-type brazing joint 


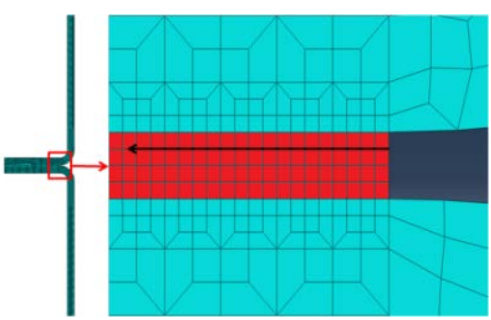

Fig.2 Meshing result of T-type brazing joint and stress analysis path1

\section{Results and analysis}

Figure 3 showed the damage contours at different times in the vincinity of the brazing area. It can be seen from the figure that the edge region of the brazing filler metal was initially damaged, which means that the creep crack propagated in the edge area at the beginning, and then it penetrated into the central area of the solder. It is when the element damage in the edge area and the central region reaches 0.99 that the failure of the brazing filler metal occours.

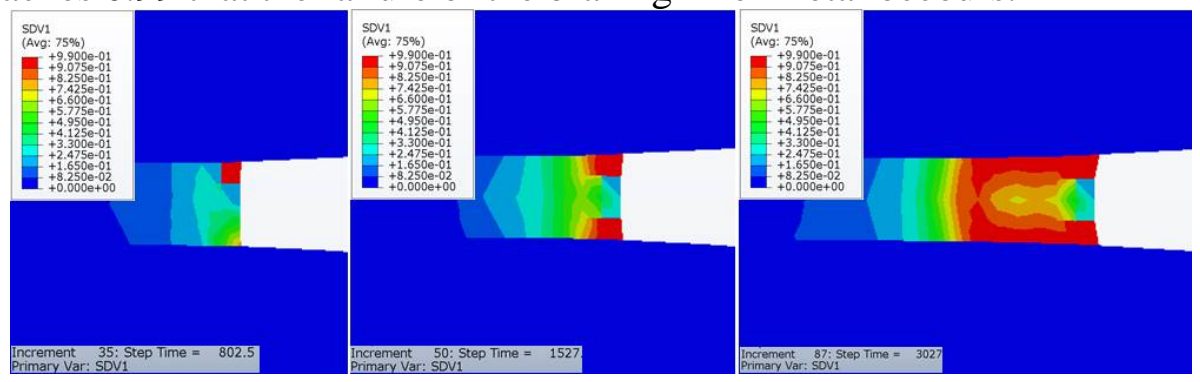

Fig.3 Creep damage contours of brazing seam at different time

Figure 4 showed the changes of the von Mises stress and damage over time for the first and second elements of the upper edge of the brazing seam. It could be seen from the figure that at the outset of creep, the stress for the first two elements were 200MPa and 150MPa respectively, and then the stresses were rapidly relaxed. The stress of the first two elements plummeted to about $100 \mathrm{MPa}$ and 70MPa respectively. Then the stress relaxation slowed down and the creep damage begin to accelerate, but the damage rate of the first element was obviously much higher than that of the second one. In 800 hours or so, the damage of the first element reached 0.99 , that was when the stress became 0 , causing the first element to fail.Then the second element stress increased obviously, which in turn caused the creep damage rate to increase obviously, and when the secend element failed, the creep crack has already propagated for one element. When the creep time approached about $1500 \mathrm{~h}$, the damage of the second element reached 0.99 , and then the stress was reduced to 0 . The creep crack finished its secend element growth.

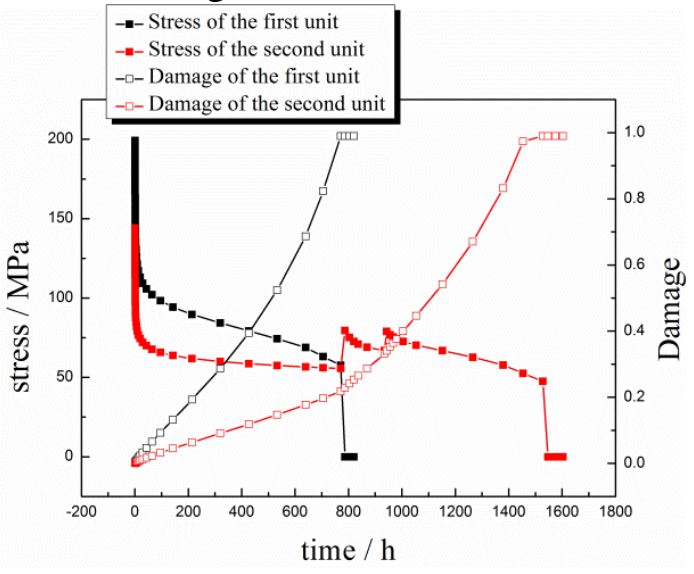

Fig.4 Stress and damage curves

Under different load conditions, the creep crack initiation times of the brazing joint were different, in general the initiation time $t_{i}$ is the time when creep crack propagate for $0.2 \mathrm{~mm}$. Figure 5 showed the effect of stress on crack initiation times under different loads. It can be seen that there 
is an approxime linear relationship between the creep initiation times and stress in the double logarithmic coordinates, and it can be expressed as power law formula $\left(t_{i}=A_{i} \sigma^{-n_{i}}\right)$. Though fitting the data in the graph, it was obtained that the constant $A_{i}=1.70616 \times 10^{50}$, and $n_{i}=10.49675$. In the actual application process, the formula can be used to predict the initiation time of a brazing joint, and then by controlling loading level to prevent the brazing joint from the premature of creep crack initiation .

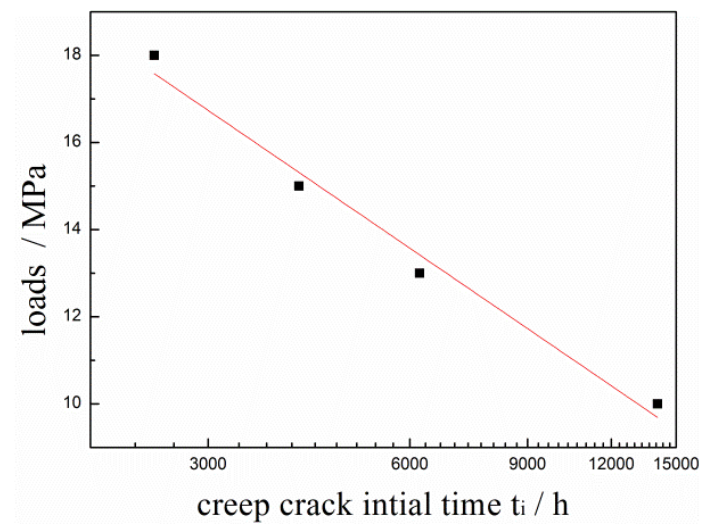

Fig.5 Crack initial time at different load levels

The thickness of the brazing filler metal is a vital process parameter in the brazed joint. The difference in thickness can exert a great impact on the stress generation and redistribution in the creep process of the brazed joint, which will further affect the initiation and growth of the creep crack. The thickness of brazing filler metal of 60,80,100, 120 and $140 \mu \mathrm{m}$ were selected to study the effect of brazing filler metal on the creep crack initiation and growth of T-brazing joints.

Based on the analysis path shown in Figure 2. Figure 6 showed the distribution of the von Mises stress on path 1 at different times. It can be seen from the figure that when the creep time nears $0 \mathrm{~h}$, the stress on the path 1 tends to decrease with the increase of the thickness of the solder layer, and the stress value decreases with the thickness of the solder in a certain area of the crack tip ;When the creep time is $2123 \mathrm{~h}$, the stress is relaxed and the stress decreases with the increase of the thickness. When the creep time is $7000 \mathrm{~h}$, the stress value of the crack tip is almost the same when the solder thickness is 60 and $80 \mu \mathrm{m}$, the stress values of thickness $60,80 \mu \mathrm{m}$ are significantly higher than those of 100,120 and $140 \mu \mathrm{m}$.It can be seen that the stress in the brazing filler metal decreases with the increase of the thickness. So a proper increase in thickness may be helpfuo to improve the creep performance of the brazed joint.
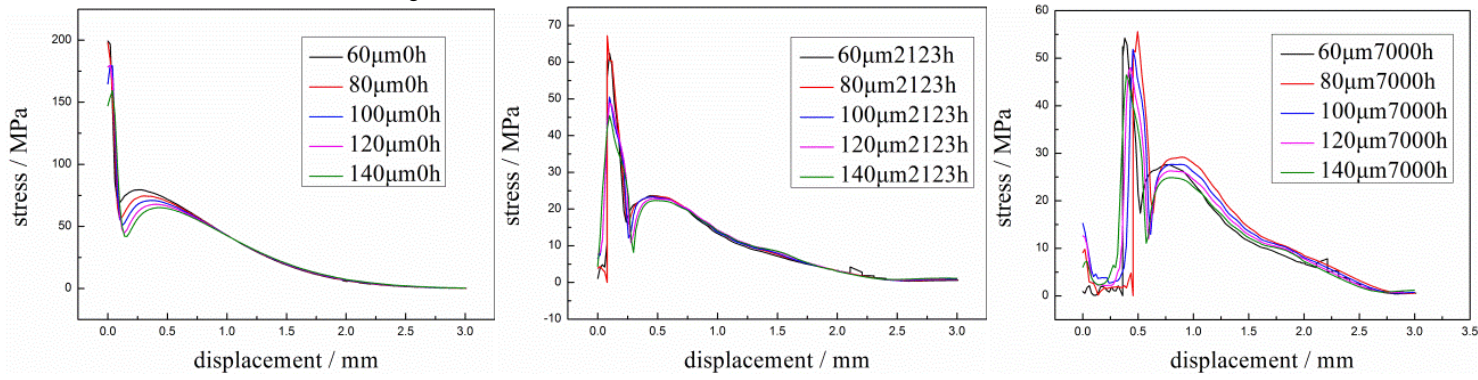

Fig.6 Varitaion of the von mises stress with the time along the path1

Figure 7 showed the variation of creep crack propagation over time at five different solder thicknesses. It can be seen from the figure that the creep crack initiation time of the solder $40 \mu \mathrm{m}$ thick is $4098 \mathrm{~h}$ while the creep crack initiation time of $140 \mu \mathrm{m}$ is about $4743 \mathrm{~h}$, which prolongs the initiation time by 15.7 percent. At the same time with the increasing thickness, the creep crack growte rate is gradually reduced. Therefore, the increase of the thickness of the solder is indeed helpful to prolong the initiation time of the brazed joint and reduce the creep crack growth rate. 


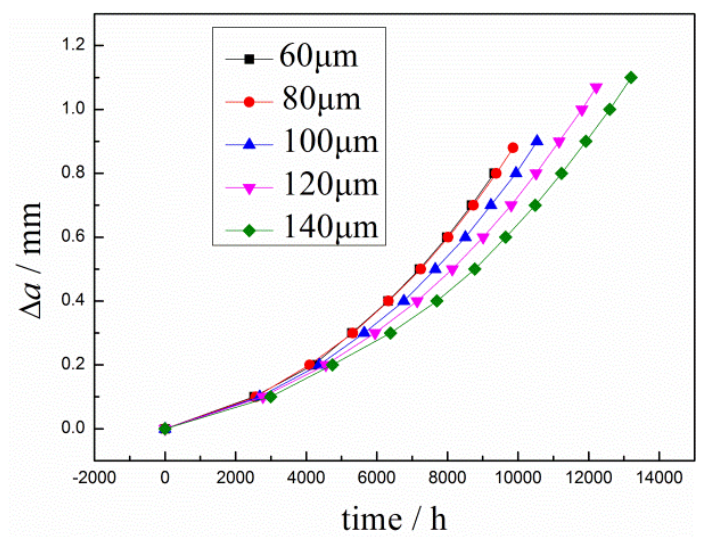

Fig.7 Effect of the brazing filler metal thickness on the creep crack growth

\section{Conclusion}

1)In the creep crack initiation stage, due to the creep deformation of the brazing filler metal, the edge of the brazing seam is damaged at first, and later on the central area of the brazing filler metal is damaged. When the damage parameter reaches 0.99, the creep crack starts to propagate.

2)The creep crack initiation time and stress satisfies the power law relationship, i.e, $t_{i}=A_{i} \sigma^{-n_{i}}$. At $650^{\circ} \mathrm{C}$, the constant $A_{i}=1.70616 \times 10^{50}, n_{i}=10.49675$. The formula can be used to predict the initiation time of the brazed joint, and then by controlling loading level to prevent creep initiation of the joint prematurely.

3)With the increase of the thickness of the solder, the von Mises stress at the crack tip decreases, the creep crack initiation time increases and the crack growth rate decreases. Therefore, a appropriate increase in the thickness of solder is helpful to improve the creep life of the T-type brazed joint.

\section{Acknowledgments}

This work was financially supported by Shanghai Pujiang Talent Project (14PJD015) fund.

\section{References}

[1] YU ZhiShui, LI RuiFen, QI Kai, et al. Interfacial structure of 316L stainless steel brazed joint using BNi-2+BNi-5 composite filler[J]. Journal of Jiangsu University of Science and Technology, 2008, 22(5): 28-32.

[2] HAN Fei, LEI Yongping, XIA Zhidong, et al.Numerical simulation of residual stress in optimization of ceramic brazing joint [J]. Welding, 2008 (6): 26-30.

[3] Tu S, Zhou G. Creep of brazed plate-fin structures in high temperature compact heat exchangers[J]. Frontiers of Mechanical Engineering in China, 2009, 4(4): 355-362.

[4] CHEN Jianjun, SHI Jin, TU Shandong. Experimental study and numerical simulation of high-temperature creep behavior of BNi-2 / 0Cr18Ni9 brazed joints [J]. Transactions of the China Welding Institution, 2006, 27 (3): 39-43.

[5] JIANG Wenchun, GONG Jianming, CHEN Hu, et al.Effect of brazing seam thickness on creep of stainless steel plate fin structure [J]. Transactions of the China Welding Institution, 2008, 29 (8): 9-12.

[6] ZHANG Yucai. Creep damage and crack growth analysis of the brazed joint under multi-axial stress state [D]. Shanghai. East China University of Science and Technology, 2016. 
[7] Latha S, Mathew M, Parameswaran P, et al. Thermal creep properties of alloy D9 stainless steel and 316 stainless steel fuel clad tubes[J]. International journal of pressure vessels and piping, 2008, 85(12): 866-870)

[8] Kumar J G, Chowdary M, Ganesan V, et al. High temperature design curves for high nitrogen grades of 316LN stainless steel[J]. Nuclear Engineering \& Design, 2010, 240(6):1363-1370.

[9] Hyde CJ, Hyde TH, Sun W, et al. Damage mechanics based predictions of creep growth in 316 stainless steel[J]. Engineering Fracture Mechanics, 2010, 77: 2385-2402.

[10] M.D. Mathew, Laha K, Ganesan V. Improving creep strength of 316L stainless steel by alloying with nitrogen[J]. Materials Science \& Engineering A, 2012, 535(2):76-83.

[11] Weil K, Koeppel B. Thermal stress analysis of the planar SOFC bonded compliant seal design[J]. International Journal of Hydrogen Energy, 2008, 33(14): 3976-3990.

[12] NI Hongfang, LING Xiang, TU Shantong.Finite element simulation of three-dimensional residual stress field in multi-pass welding [J]. Mechanical Strength, 2004, 26 (2): 218-222.

[13] Hyde T, Xia L, Becker A. Prediction of creep failure in aeroengine materials under multi-axial stress states[J]. International journal of mechanical sciences, 1996, 38(4):385-403. 